\title{
Challenges in Cost Modelling of Recycling Carbon Fiber Composites
}

\author{
Essam SHEHAB ${ }^{\mathrm{a}, 1}$, Arshyn MEIIRBEKOV ${ }^{\mathrm{a}}$ and Shoaib SARFRAZ ${ }^{\mathrm{b}}$ \\ ${ }^{a}$ School of Engineering and Digital Sciences, Nazarbayev University, Nur-Sultan, \\ Kazakhstan \\ ${ }^{\mathrm{b}}$ Manufacturing department, School of Aerospace, Transport and Manufacturing, \\ Cranfield University, Cranfield, Bedfordshire, MK 43 0AL, UK
}

\begin{abstract}
The use of carbon fiber composites (CFCs) has become broad in many industries due to its superior properties compared to conventional materials. However, the increased demand coupled with environmental regulations has led to the development of different recycling methods for CFCs such as mechanical, thermal and chemical processes. Each recycling method has its own requirements and outputs along with some economic implications which need to be justified through cost modelling. This paper aims to identify current challenges associated with cost modelling of different processes for CFC recycling. The main challenges identified are grouped into three main categories such as technical issues, supply chain and market challenges.
\end{abstract}

Keywords. Cost Modelling, Carbon Fiber Composites, Recycling, Challenges.

\section{Introduction}

Composite materials find their application in a wide range of industries, such as construction, automotive and aerospace, because of their high strength, high stiffness, lower weight, as well as high thermal and chemical stability in inert conditions. Among different types of composites, carbon fiber composites (CFCs) are not exposed to stress corrosion or rupture at normal temperatures, which is typical for glass and organic polymers. They are appropriate for use in applications where strength, stiffness in pair with lower weight are the key requirements [1]. Hence, CFCs are extensively used in the aircraft industry due to their lightweight properties and actually contribute to the reduction of emissions from flights. Indeed, more than $50 \%$ of the weight of new aircraft such as the Airbus A350 is composed of CFCs [2]. Overall, the annual demand for CFCs was approximately 100000 tons in 2019 . The market of carbon composites is growing at a rate of $10-12 \%$ annually due to the increased usage of carbon fibers in aerospace, wind turbine blades and other applications [3]. The overall breakdown of CFC applications by market segments is illustrated in Figure 1.

\footnotetext{
${ }^{1}$ Corresponding Author, Mail: essam.shehab@nu.edu.kz.
} 


\section{CFC usage by the market segment}

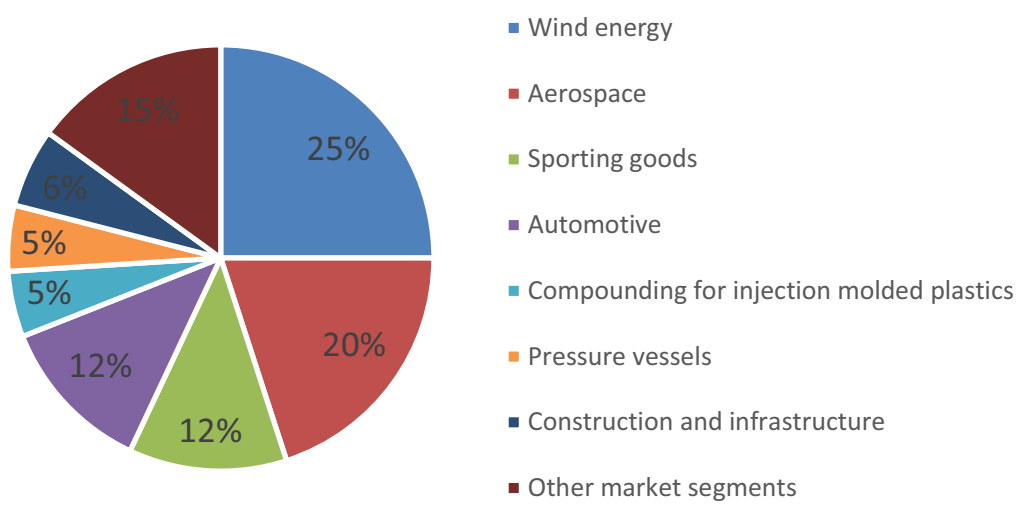

Figure 1. Breakdown of CFC application by the market segments [3]

Despite all the advantages CFCs offer, their increased usage has led to the generation of enormous amounts of CFC waste. It is stated that approximately $40 \%$ of all the composite material waste corresponds to manufacturing waste, and about $60 \%$ consists of woven trimmings [2]. The transportation industry accounts for almost $50 \%$ of the total amount, which creates a significant concern to create an environmentally and economically effective route for disposal of end-of-life products [4]. By 2025, 8500 planes with composite structures are going to be decommissioned, where each aircraft contribute 20 tons of CFC waste [5]. All of the waste products have to be managed with a minimum impact on the environment and maximum benefits for the producers.

For many years, landfilling was the only option for composite waste. However, from the End-Of-Life Vehicle Directive (Directive 2000/53/EC), the disposal requirements emerged: starting from 2015 , recycling or reuse is obligatory for $85 \%$ of the weight of any end-of-life vehicle, and $10 \%$ of it for the energy recovery. Whereas, only $5 \%$ of the weight can be landfilled [6]. In other words, now vehicle manufacturers must consider recycling pathways for end-of-life vehicles, which in turn can be partially made from composite materials.

The industrial sectors that use CFCs are informed about legislation updates and uprising trends for sustainable green development. As now they are forced to recycle composite materials due to legislation, it is essential to estimate the costs of CFCs recycling for different methods of recycling. The data related to the recycling of composites is far scarcer compared to that of metallic components. Manufacturers do need to know about the cost drivers and the level of investment required to recycle such materials at the design stage. However, the development of cost models for CFC recycling faces some challenges and issues. This work aims to review those challenges associated with the cost modelling of CFCs recycling (mechanical, chemical and thermal treatments) by bringing a transdisciplinary perspective to the problem. Developing a cost model for composites recycling requires both a deep understanding of recycling processes and cost modelling techniques. 


\section{State of the art}

The business is now as global as has never been before; hence, cost minimization is an essential key success factor in the market. It is important for companies to know the costs associated with CFC recycling processes for determining their success or failure. Both the manufacturing waste and end of life composites are usually disposed of using landfill or incineration. These disposal methods are not optimum, also environmental regulations have banned incineration and landfill of composites waste [7]. The best method to deal with such a challenge is recycling. According to Carberry [5], the manufacturing cost of recycled carbon fiber is $70 \%$ less as compared to virgin carbon fiber, also very less amount of energy is consumed for its manufacturing ( $98 \%$ less as compared to $\mathrm{vCF}$ ). This encourages the recycling of composites.

Carbon fiber composites are difficult to recycle because: (i) thermosets are crosslinked and cannot be remelted and remoulded compared to thermoplastics; (ii) CFCs usually include inserts, cores, coatings, and removing these is time-consuming and difficult to automate and (iii) CFC composition vary extensively making the collection and separation of waste materials difficult [2]. Different methods available for the recovery of used CFCs are mechanical treatment, thermal treatment and chemical recycling, they are explained below.

Mechanical recycling is a conventional method of recycling during which several steps are carried out in order to cut and mill down the material to transform into short fibers (powder). Several companies applied mechanical recycling to thermosets, such as ERCOM in Germany and Phoenix in Canada [8]. Overall, the advantage of this process is that it does not involve any use of hazardous materials for both fibers and resins. However, there are many limitations associated with mechanical recycling. Firstly, the recycled product is either in the form of powder or short fibers, which extremely restricts the area of application of the secondary product. As a result of the quality of fibers, the mechanical properties of the recycled product allows to use them only as a filler reinforcement in new composites [2]. With the current prices for fillers such as calcium carbonate, the application of the recycled product as fillers can be questionable [8]. Secondly, the steps required to transform recyclate into powder are highly energyintensive, which affects the financial viability of the process [9]. This may explain that ERCOM terminated its activity after 14 years due to financial problems.

The two main thermal methods (pyrolysis and fluidized bed recycling) are considered in this paper, as these are the only thermal methods which result in the recovery of the most valuable part of the composite - carbon fibers.

Pyrolysis is the thermal treatment of the material in the absence of oxygen. During pyrolysis, the temperature is heated up to 450 to $700 \mathrm{C}$, the matrix is decomposed into lower-weight molecules, while carbon fibers stay intact [2]. The variation of the mechanical properties degradation for pyrolysis is $4 \%$ to $20 \%$ compared to vCF [9]. However, the final properties of the product are highly dependent on the parameters used for the process. If the oxygen content and temperature are not controlled, the fiber properties can degrade remarkably due to pyrolytic char on the surface of fibers. [2]. Several attempts have been made to modify this method in order to eliminate pyrolytic char and preserve original properties. The methods are catalytic, vacuum and microwave pyrolysis processes. However, only microwave treatment and catalytic pyrolysis processes achieved the desired results with clean recovered fibers [9].

Overall, pyrolysis is the most widespread method to recycle CFCs in the industry. The technique does not involve any chemical solvents and is self-preserving in terms of 
energy by using gases to heat the chamber or produce the electricity [8]. Witik et al. [10] stated that pyrolysis requires only $5-10 \%$ of the energy required to produce vCF. A recent study by Guo et al. [11] demonstrated that recycled carbon fiber from the composite with epoxy resin had maintained comparable properties to $\mathrm{vCF}$ and can be used as short-cut rCFs in primary productions such as brake pads.

In the fluidized bed process, the size of the composite is reduced to be fed into a fluidized bed. The bed consists of silica sand of $0.85 \mathrm{~mm}$ in size. By fluidizing the sand with a stream of air at temperatures of 450-550 $\mathrm{C}^{\circ}$ having velocity in the range of $0.5-1$ $\mathrm{m} / \mathrm{s}$, the polymer matrix is vaporized, allowing fibers and fillers to be carried out in the gas stream. Then the fibers and fillers can be separated in a cyclone. Finally, fibers and fillers must be processed in a second chamber with a higher temperature $\left(1000 \mathrm{C}^{\circ}\right)$ to fully recover the fibers $[2,10]$. The advantage of this process is that it is tolerant for mixed and contaminated materials with metal inserts, which is the usual case for end-oflife vehicle components. Besides, the gases generated during the process can be used as a source of energy [8]. The resulting fibers do not show oxidation on the surface, hence, demonstrating good potential for bonding in a new polymer matrix. However, the mechanical properties of fibers are degraded up to $20 \%$ and their structure is damaged. The appropriate possibility to reuse products of this process are materials with short discontinuous fibers such as moulding compounds [4].

The chemical process for CFCs recycling is named as solvolysis and is further categorized as solvolysis at lower temperatures and solvolysis in supercritical fluids. Solvolysis at lower temperature utilizes reactive medium such as alcohol, or glycol to break down the polymer matrix structure. The process ends with fibers, other inorganic elements and excess solvent. Liu et al. [12] conducted an experiment on CFC by desolving it in nitric acid. The recycled fibers had only $1.1 \%$ loss in tensile energy. Compared to the methods discussed above, solvolysis at a lower temperature is efficient in terms of preserving the mechanical properties of fibers. However, the chemicals used in the process are hazardous and may have an environmental and health impact.

Solvolysis of CFCs in near or supercritical fluids has been developed for polymers in Japan since 1995 and is constantly being innovated. Supercritical fluid is any fluid which has temperature and pressure beyond its critical point with no distinct phase that allows its use as a solvent for industrial processes. Okajima et al. [13] was a pioneer in using supercritical water at $300-450 \mathrm{C}^{\circ}$ to recycle epoxy resin/carbon fiber. The results showed loss of tensile strength up to $10 \%$ for a single fiber. Jiang et al. [14] and Henry et al. [15] conducted experiments on carbon fiber reinforced epoxy resin using alcohol and a mixture of water and methanol, respectively. Both studies achieved reclamation of fibers with mechanical properties close to $\mathrm{VCF}$.

Overall, the use of supercritical fluids has shown itself as an excellent option for recycling carbon fibers in polymer composites. However, it is necessary to investigate critical parameters of the process, such as type of fluid, temperature, pressure, time and type of a chamber used. Finally, solvolysis is very sensitive to contaminants in the waste. Hence, initial preparation and cleaning of the waste requires additional efforts.

From the review, it is clear that CFC recycling methods are evolving, each method has its drawbacks. The next section will group and discuss challenges related to cost modelling of processes for CFC recycling. 


\section{Issues and Challenges}

Cost modelling of CFCs would provide a good understanding for manufacturers in deciding whether recycling or disposal of composites is financially viable. However, there are many technical and other types of challenges towards creating a practical cost modelling framework for different recycling methods. The main challenges related to cost modelling is related to identifying cost drivers - any part of the process which affects the final cost of a recycling process. For instance, direct cost drivers of mechanical recycling and pyrolysis, such as materials, machinery and labor are briefly discussed by Shehab et al. [16]. However, this type of data is not usually provided in detail by the researchers nor industry members and can be a possible obstacle in developing an effective cost model. In addition to the technical issues, other indirect challenges also have an influence on the cost modelling of CFCs. The challenges towards cost modelling of CFCs recycling processes are presented in Figure 2. The major issues and challenges consist of technical issues, supply chain and networking and market challenges, which are described further in detail in the following subsections.

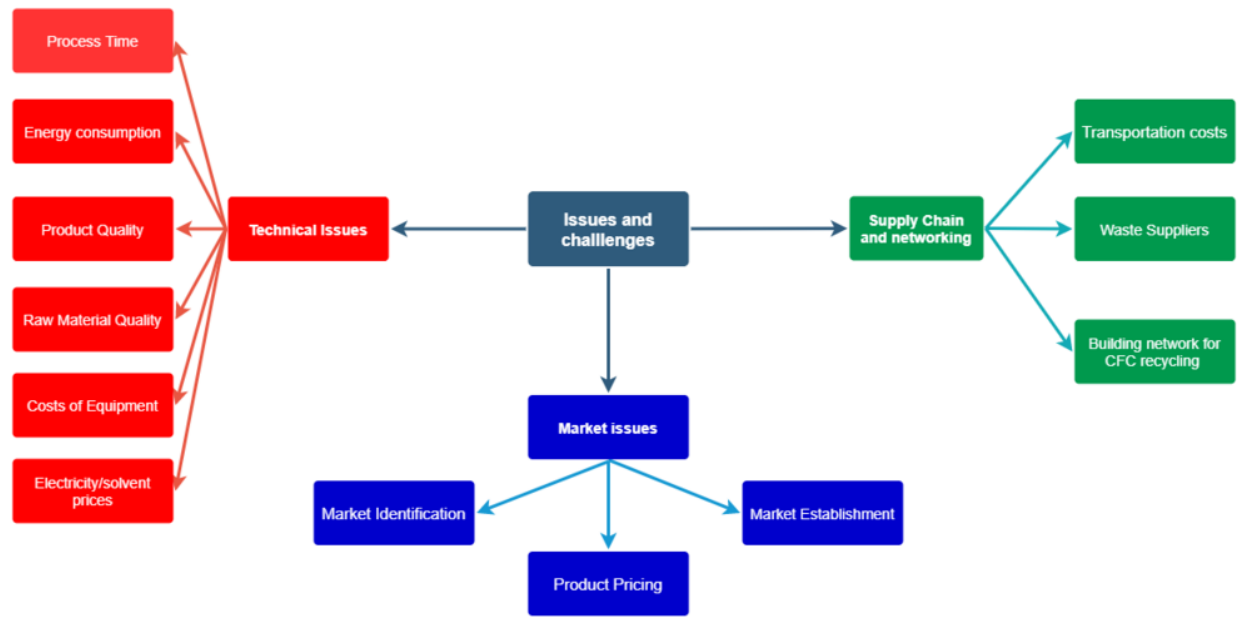

Figure 2. Challenges of CFC recycling.

\subsection{Technical Issues}

As it was discussed before, all CFC recycling processes have their own advantages and drawbacks. However, there are certain parameters that affect each of them in terms of cost modelling. For instance, energy consumption is one of the significant technical issues in recycling CFCs. It is essential that the energy spent on recycling CFC waste must be as low as possible since manufacturing vCF consumes $183-286 \mathrm{MJ} / \mathrm{kg}$, which is 10 times higher compared with glass fiber [17]. It is a critical requirement for a recycling process to be energy-efficient. Hence, it is important to consider energy consumption in cost modelling for recycling CFCs. Taking into account that the data related to recycling composites is limited, identifying energy consumption rates for different recycling processes would be challenging. 
Another obstacle for cost modelling of the recycling processes is the variety of raw material quality. Different end-of-life products and manufacturing waste have different types of polymers and contaminants, which create problems for separation and sorting. Hence, different materials require different levels of initial treatment before the primary process, which again may affect the costs of the process. The accuracy of cost modelling will definitely be affected by this issue if not properly treated. Developing a cost model that would consider the variations of raw material would be a challenging job.

The quality of recycled carbon fiber is dependent on the process selected and its parameters. It is a direct cost driver of the process, which defines the cost of the final product. As all methods have different output quality, it is a vital technical issue to maintain characteristics of rCFs comparable to vCFs.

There are other parameters that affect cost modelling of recycling CFs such as the equipment, electricity and components costs for recycling CFCs, which is unique for every process and location of the enterprise. Hence, it is essential to consider all parameters that may have an effect on the costs of recycling.

\subsection{Supply chain and Networking}

The first input for any recycling process is waste, hence, waste suppliers have to cooperate with recyclers supplying them regularly with waste in an appropriate form. The variation of suppliers and their reliability will have an effect on cost modelling of the recycling process. In general, building networks between $\mathrm{CFC}$ community members such as recyclers, suppliers and researchers is a critical challenge for the further development of the topic. It will define the quality, accuracy and relevance of the data, which is necessary to build effective cost models for CFC recycling.

In addition to that, as the recyclers and suppliers may be located at significant distances away from each other, transportation costs have a major influence on the final costs of the recycling process. It is necessary to continuously improve processes in terms of the supply chain and reduce overall costs. Effective cost models must take into account transportation costs before the recycling process is initiated.

\subsection{Market Challenges}

Recycled carbon fiber's application is limited due to its degraded mechanical characteristics and surface properties. Hence, the characteristics of different rCFs have to be known in order to label them and identify in which area they can be utilised [2]. Depending on the origin and final characteristics of the product, values for the recycled label can be assigned for the market. Product pricing will be another issue, as all the processing times and costs have to be adequately assessed. Lastly, the establishment of the market will be a major challenge. The key factor which predetermines the successful use of recycled carbon fiber is finding an appropriate use for the recycled products with their degraded properties. Up until now, this challenge has not been overcome and demand for $\mathrm{rCF}$ products in the market is still vague. The establishment of a market requires that all challenges discussed above have been overcome so that the general image of the rCFs should be robust enough to be reused as a cost-effective and environmentally friendly material.

Another concern related to cost modelling of CFCs recycling is that the industry members usually hesitate to disclose the details of their work, such as process parameters, recycled material properties, pricing, etc., to protect their competitive advantage in the 
market. This is an essential issue as cost modelling based on case studies conducted with companies would be more accurate compared to using data from the literature, which could be obsolete as time passes.

All the mentioned challenges in this section might have a significant effect on the reliability of results of the cost modelling framework. An effective cost model of recycling should include all the aspects discussed such as the technical parameters of the process, final prices of the recyclate, transportation costs, etc. For instance, Dong et al. [18] provided an economic model to assess the recovery pathways of carbon fiber. According to the authors, the unit costs of recovered carbon fiber were lower compared to the results of another research due to the limitation of the study, such as not considering the exogenous factors (type of waste, transportation, packaging, etc). This work highlights these factors in order to provide a robust cost modeling framework in the next stages of the project.

\section{Conclusions}

This work outlined the current state of CFC recycling industry and identified the main issues and challenges for the development of cost models of CFC recycling processes. Three main elements: Technical, Supply Chain and Market challenges are discussed in detail with their sub-elements.

It is found that there are many technical challenges associated with recycling $\mathrm{CFC}$, such as energy consumption and variation of both raw materials and output recovered fibers. For the supply chain, dependence on waste suppliers and overall networking between CFC community members are highlighted. Finally, the current market for recycled carbon fiber is not established, which represents one of the key challenges in the success of CFC recycling.

This paper is a part of an ongoing project which aims to develop cost modelling methodologies for recycling and disposal of composite materials. In the future, identified key challenges could be a useful input in identifying cost drivers by providing a view on underlying factors that could affect costs. The next stage of the project is to develop a library of cost drivers and objects for cost estimation with the uncertainties and risks which could have an impact on them. By building case studies with industry members, eventually, cost modelling frameworks would be developed to predict recycling costs at the conceptual design stage.

\section{Acknowledgements}

The authors want to express their sincere gratitude to the Government of Kazakhstan and Nazarbayev University for funding this research study under their project's number: SOE2019006 - 15882944.

\section{References}

[1] S. Chand, Review carbon fibers for composites, Journal of Materials Science, Vol. 35, 2000, pp. 1303-1313.

[2] S. Pimenta and S. T. Pinho, Recycling carbon fibre reinforced polymers for structural applications: 
Technology review and market outlook, Waste Management, vol. 31, 2011, pp. 378-392.

[3] S. Mazumdar et al., 2020, Composites Manufacturing: 2020 State of the Industry Report, Accessed: 23.04.2020. [Online]. Available: http://compositesmanufacturingmagazine.com/2020/01/2020state-of-the-industry-report/

[4] S. J. Pickering, R. M. Kelly, J. R. Kennerley, C. D. Rudd, and N. J. Fenwick, A fluidised-bed process for the recovery of glass fibres from scrap thermoset composites, Composites Science and Technology, vol. 60, 2000, pp. 509-523.

[5] W. Carberry, Airplane recycling efforts benefit boeing operators, Boeing AERO Magazine QRT, vol. 4, 2008, pp. 06-13.

[6] E. U. Directive, 53/EC of the European Parliament and of the Council of 18 September 2000 on endof life vehicles, Official Journal of the European Union, vol. L 269, 2000, pp. 34-42.

[7] Y. Yang et al., Recycling of composite materials, Chemical Engineering and Processing: Process Intensification, vol. 51, 2012, pp. 53-68.

[8] S. J. Pickering, Recycling technologies for thermoset composite materials-current status, Composites Part A: Applied Science and Manufacturing, vol. 37, 2006, pp. 1206-1215.

[9] C. Morin et al., Near- and supercritical solvolysis of carbon fibre reinforced polymers (CFRPs) for recycling carbon fibers as a valuable resource: State of the art, The Journal of Supercritical Fluids, vol. 66,2012 , pp. 232-240.

[10] R. A. Witik et al., Carbon fibre reinforced composite waste: An environmental assessment of recycling, energy recovery and landfilling, Composites Part A: Applied Science and Manufacturing, vol. 49, 2013, pp. 89-99.

[11] W. Guo et al., Recycling carbon fiber-reinforced polymers by pyrolysis and reused to prepare shortcut fiber C / C composite, Journal of Reinforced Plastics and Composites, vol. 38, 2019, pp. 340348.

[12] Y. Liu et al., Recycling of carbon/epoxy composites, Journal of Applied Polymer Science, vol. 94, 2004, pp. 1912-1916.

[13] I. Okajima et al., Decomposition of epoxy resin and recycling of CFRP with sub-and supercritical water, Kagaku Kogaku Ronbunshu, vol. 28, 2002, pp. 553-558.

[14] G. Jiang et al., Characterisation of carbon fibres recycled from carbon fibre/epoxy resin composites using supercritical n-propanol, Composites Science and Technology, vol. 69, 2009, pp. 192-198.

[15] L. Henry et al., Semi-continuous flow recycling method for carbon fibre reinforced thermoset polymers by near- and supercritical solvolysis, Polymer Degradation and Stability, vol. 133, 2016, pp. 264-274.

[16] E. Shehab, G. Alanazi and S. Sarfraz, Towards Recycling Cost Modelling Framework for Carbon Fibre Composites, Advances in Transdisciplinary Engineering, Vol. 10, 2019, pp. 593-602.

[17] X. Li, R. Bai, and J. Mckechnie, Environmental and financial performance of mechanical recycling of carbon fibre reinforced polymers and comparison with conventional disposal routes, Journal of Cleaner Production, vol. 127, 2016, pp. 451-460.

[18] P. A. V. Dong, C. A-Pantel and A-L. Cadene, Economic and environmental assessment of recovery and disposal pathways for CFRP waste management, Resources, Conservation and Recycling, vol. 133, 2018,pp. 63-75. 